\title{
High-speed vibration-milling-promoted synthesis of symmetrical frameworks containing two or three pyrrole units
}

\author{
Marco Leonardi, Mercedes Villacampa and J. Carlos Menéndez*
}

\author{
Full Research Paper \\ Address: \\ Departamento de Química Orgánica y Farmacéutica, Facultad de \\ Farmacia, Universidad Complutense, 28040 Madrid, Spain \\ Email: \\ J. Carlos Menéndez* - josecm@ucm.es \\ * Corresponding author \\ Keywords: \\ diversity-oriented synthesis; mechanochemistry; multicomponent \\ reactions; pyrroles; solvent-free synthesis
}

\author{
Beilstein J. Org. Chem. 2017, 13, 1957-1962. \\ doi:10.3762/bjoc. 13.190 \\ Received: 12 June 2017 \\ Accepted: 28 August 2017 \\ Published: 15 September 2017 \\ This article is part of the Thematic Series "Mechanochemistry". \\ Guest Editor: J. G. Hernández \\ (C) 2017 Leonardi et al.; licensee Beilstein-Institut. \\ License and terms: see end of document.
}

\begin{abstract}
The pseudo-five-component reaction between $\beta$-dicarbonyl compounds ( 2 molecules), diamines and $\alpha$-iodoketones ( 2 molecules), prepared in situ from aryl ketones, was performed efficiently under mechanochemical conditions involving high-speed vibration milling with a single zirconium oxide ball. This reaction afforded symmetrical frameworks containing two pyrrole or fused pyrrole units joined by a spacer, which are of interest in the exploration of chemical space for drug discovery purposes. The method was also extended to the synthesis of one compound containing three identical pyrrole fragments via a pseudo-seven-component reaction. Access to compounds having a double bond in their spacer chain was achieved by a different approach involving the homodimerization of 1-allyl- or 1-homoallylpyrroles by application of cross-metathesis chemistry.
\end{abstract}

\section{Introduction}

Symmetrical molecules formed by two or more pharmacophoric units joined by a spacer are very important in drug discovery because many drug targets are symmetrical, the reason most often being that they are composed by two or more identical subunits. Some examples of therapeutic targets in which symmetrical bivalent ligands have proved to be useful include the protease of the human immunodeficiency virus HIV [1], cellular prion protein, $\operatorname{PrP}^{\mathrm{c}}$ [2], and the transient receptor potential melastatin 8 (TRPM8) channel receptor [3]. The syn- thesis of these symmetrical molecules normally relies on multistep sequences. Due to the special relevance of nitrogen heterocycles in the generation of bioactive molecules, medicinal chemists would greatly benefit from the ability to build two heterocyclic systems at both ends of the spacer chain in a single maneuver. Further advantages in terms of synthetic efficiency would be gained if the key operations leading to the buildup of the heterocyclic frameworks could be performed using multicomponent reactions. However, the simultaneous construction 
of two heterocycles in a single operation by means of such reactions has very little precedent in the literature and has never been achieved under mechanochemical conditions.

In this context, we present here our results on the development of pseudo-five-component reactions allowing the construction of bispyrrolic systems 1 starting from $\beta$-dicarbonyl compounds $\mathbf{2}$, diamine derivatives $\mathbf{3}$ and aryl ketones $\mathbf{4}$, together with some related additional methodology. The disconnection employed and the structural diversity introduced at the three reaction components is summarized in Scheme 1.

Our procedure involves the use of mechanochemistry, which deals with reactions promoted by mechanical energy and is emerging in recent years as a versatile tool that allows solventfree approaches to organic and inorganic synthesis [4-13]. Indeed, the protocol reported here can be viewed as a generalization of our previously published pyrrole synthesis based on the reaction between primary amines, $\beta$-dicarbonyl compounds and ketones, promoted by high-speed vibration milling (HSVM) $[14,15]$. The importance of pyrrole frameworks stems from the status of this heterocycle as a privileged structure in drug discovery due to its presence as a structural core in molecules that are able to bind various receptors [16].

\section{Results and Discussion}

Our route to the target bispyrrole systems is summarized in Scheme 2. Treatment of aromatic ketones 4 with $N$-iodosuccin- imide (NIS) in the presence of toluenesulfonic acid under highspeed vibration milling for $1 \mathrm{~h}$ afforded $\alpha$-iodoketones $\mathbf{6}$, which were not isolated. The suitable $\beta$-dicarbonyl compound $\mathbf{2}$ and $\alpha, \omega$-diamine 3 plus a catalytic amount of Ce(IV) ammonium nitrate (CAN) [17], which had been previously pre-mixed for 30-60 min to ensure the complete generation of the intermediate bis- $\beta$-enaminones $\mathbf{5}$, were added to the reaction vessel, together with silver nitrate, and the mixture was again submitted to milling for an additional hour. The reactions were routinely performed from $1 \mathrm{mmol}$ of the starting materials, but two of them (leading to compounds $\mathbf{1 a}$ and $\mathbf{1 n}$ ) were also carried out at a $10 \mathrm{mmol}$ scale without any significant loss in yield.

This solvent-free protocol combines the initial $\alpha$-iodination of the starting ketone $\mathbf{4}$ with a three-component pyrrole synthesis related to the classical Hantzsch reaction. The intermediacy of species $\mathbf{5}$ and $\mathbf{6}$ was proved by the following experimental observations:

1. They could be isolated by suitably interrupting our process. As a representative example, the bis- $\beta$-enaminone arising from methyl acetoacetate and 1,4-butanediamine was isolated in quantitative yield after mixing the starting materials in the presence of 5\% CAN. The isolation and characterization of the intermediate $\alpha$-iodoketones has been reported previously [15].

2. The isolated intermediates reacted under our usual conditions to give pyrrole derivatives $\mathbf{1}$.

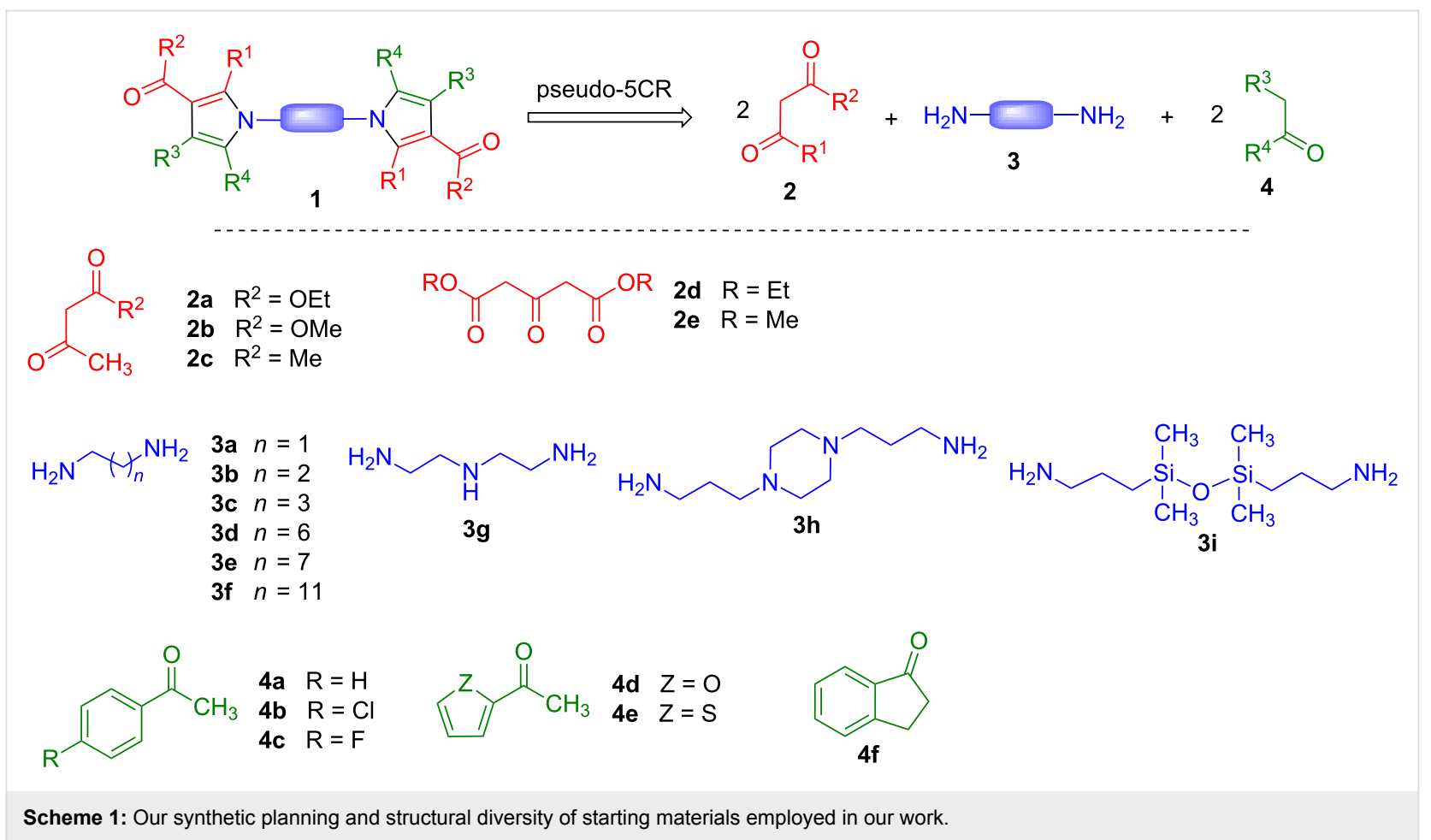




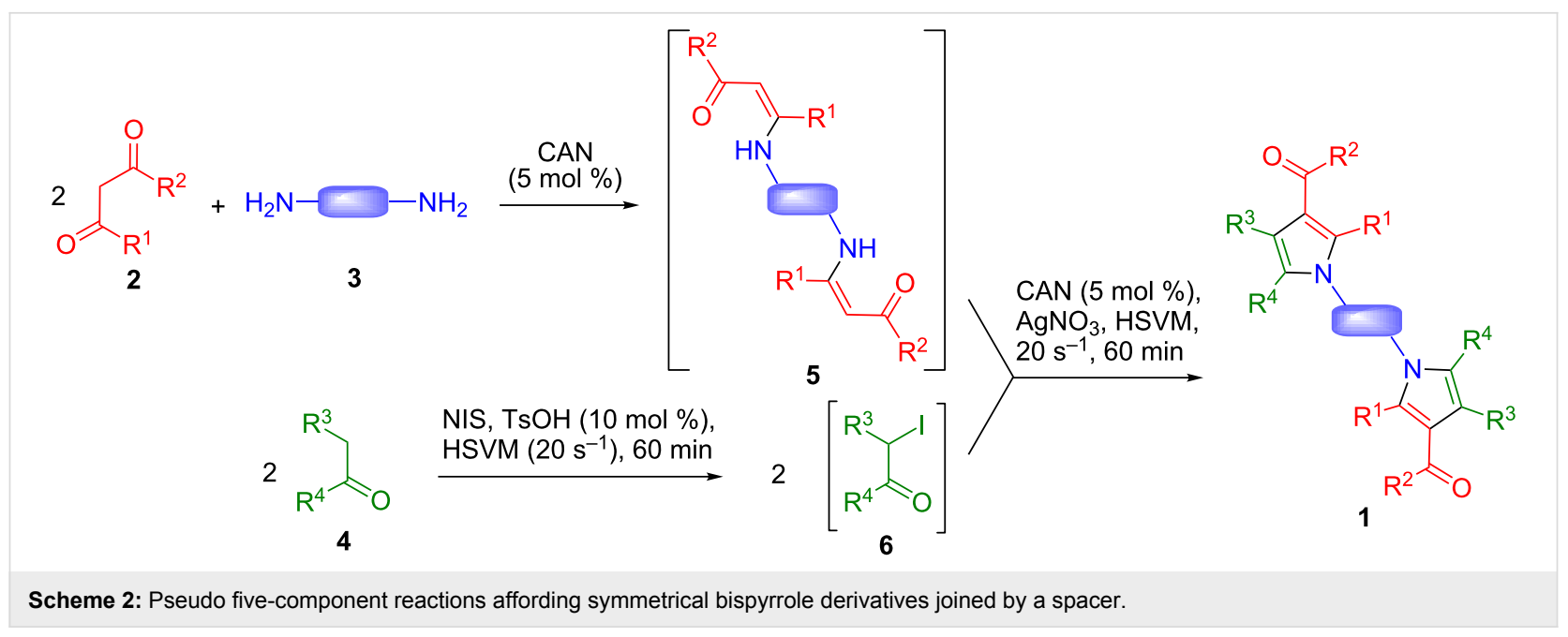

In some cases (compounds $\mathbf{1 d}, \mathbf{1 g}, \mathbf{1 j}, \mathbf{1 1}, \mathbf{1 m}, \mathbf{1 0}$ ), the ball milling-promoted iodination step failed and it was necessary to obtain the $\alpha$-iodoketones $\mathbf{6}$ in a separate step by treatment of $\mathbf{4}$ with $\mathrm{I}_{2}$ and $\mathrm{CuO}$ in methanol. The iodination of 1-indanone (eventually leading to 1o) may be hampered by steric hindrance, since this is the only case where $\mathrm{R}^{3}$ is different from $\mathrm{H}$. In the cases of 2-furyl methyl ketone and 2-thienyl methyl ketone, the reason for the lower reactivity under solvent-free conditions may be the stabilization of the intermediate enol via intramolecular hydrogen bonding, which would be disrupted in the alternative conditions involving the use of methanol as solvent.

The scope of the method is summarized in Figure 1. In some cases (compounds $\mathbf{1 a}-\mathbf{g}$ ) the spacer was simply a polymethylene chain, but the inclusion of spacer chains containing an amino group $(\mathbf{1} \mathbf{h})$, piperazine $(\mathbf{1} \mathbf{i}, \mathbf{j})$ or tetramethyldisiloxane (1k-o) fragments, was also feasible. Interestingly, the use of $N^{1}$-(2-aminoethyl)ethane-1,2-diamine as the starting material was also possible, without interference from the secondary amino group in spite of its nucleophilicity, to give compound 1h. This kind of functionalized spacers is interesting in that they may allow additional interactions with biological targets. Furthermore, the tetramethyldisiloxane derivatives are of relevance in view of the current interest in silicon-containing compounds for drug discovery applications, which has led to the "silicon switch" approach to the design of bioactive molecules [18-20]. Regarding the pyrrole rings, they were generally methyl-substituted at C-2, but the attachment of functional groups to the methyl substituent was also possible, as shown by the preparation of compounds $\mathbf{1 g}$ and $\mathbf{1 n}$. Ketone (compounds 1f and $\mathbf{1 j}-\mathbf{l}$ ) and ester functions (compounds $1 \mathbf{a}-\mathbf{e}, \mathbf{1 g}-\mathbf{i}$ and $\mathbf{1 m - 0 )}$ could be present at C-3, although an attempt to introduce an amide was unsuccessful. A variety of aromatic and heteroaromatic rings could be present at the C-5 position, and the synthesis of compound 10 from 1-indanone proved the pos- sibility to prepare systems containing two linked fused pyrrole moieties.

The advantages of the mechanochemical Hantzsch protocol over the conventional one in solution in terms of yield, reaction time and, in most cases, the possibility to telescope the formation of the $\alpha$-iodide and the pyrrole synthesis in a single process have been previously established [15]. Nevertheless, in order to achieve a more reliable extension of this conclusion to the pseudo-5CR reactions described in the present article, we have performed a control experiment with the reaction leading to $\mathbf{1 c}$ and observed a significantly lower yield (47\% vs $62 \%)$ and a longer reaction time ( $5 \mathrm{~h}$ vs $2 \mathrm{~h}$ ) in solution.

The use of triamine 7 as the starting material allowed the preparation of compound $\mathbf{8}$ via a pseudo-seven-component reaction (Scheme 3). While the overall yield was only moderate, it has to be taken into account that the preparation of $\mathbf{8}$ involves 12 individual steps, with a linear sequence comprising 9, and thus the average yield is $89 \%$ per step. In view of its functionalization, compound 7 can be regarded as a good precursor to heterocyclic dendrimeric structures.

As an additional entry into symmetrical systems containing two pyrrole structural fragments, we briefly examined the homodimerization reactions of 2-allyl- and 2-homoallylpyrroles via cross-metathesis, which should give access to spacers not easily accessible by the previously described route. The starting materials for this study (compounds 11) were readily prepared under the conditions for single-ring pyrrole derivatives $[14,15]$ and, as shown in Scheme 4, they were uneventfully transformed into the target compounds $\mathbf{1 2}$ in the presence of the second-generation Hoveyda-Grubbs catalyst and copper(I) iodide. Interestingly, the reactions starting from 1-allylpyrroles gave a single stereoisomer at the central double bond, which was assumed to 


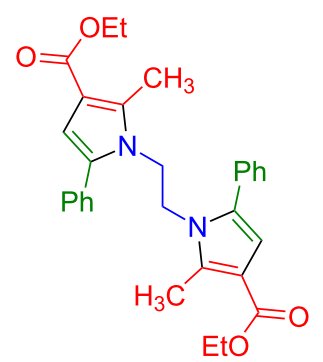

$1 \mathrm{a}(60 \%)$

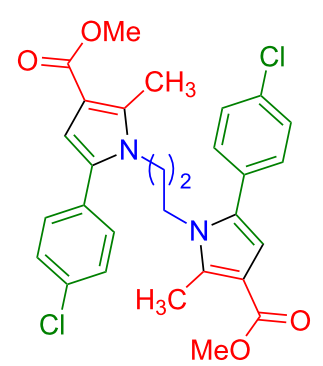

1b $(66 \%)$

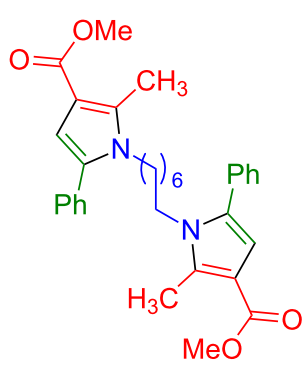

1e $(59 \%)$

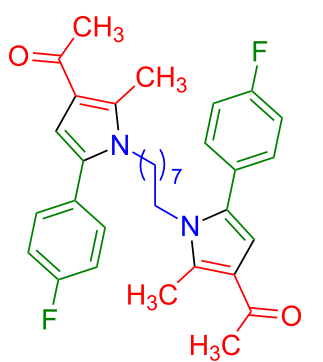

If $(60 \%)$

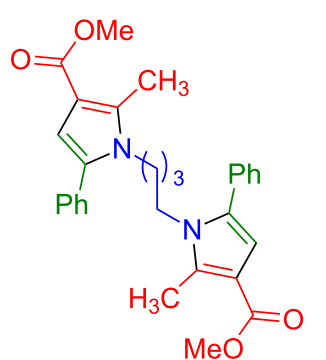

1c $(62 \%)$

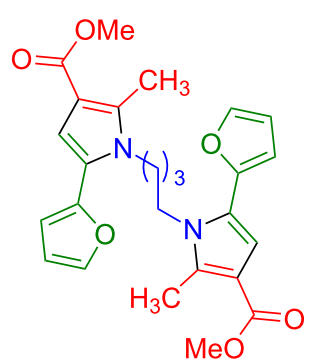

1d $(68 \%)$<smiles>CCOC(=O)c1cc(-c2ccccc2)n(CCCN2CCN(CCCn3c(-c4ccccc4)cc(C(=O)OCC)c3C)CC2)c1C</smiles>

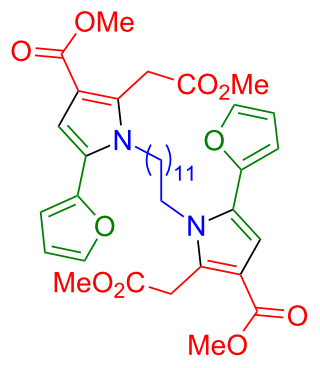

1g $(60 \%)$<smiles>CCOC(=O)c1cc(-c2ccccc2)n(CCNCCn2c(-c3ccccc3)cc(C(=O)OCC)c2C)c1C</smiles>

1h $(74 \%)$<smiles>CC(=O)c1cc(-c2ccco2)n(CCCN2CCN(CCCn3c(-c4ccco4)cc(C(C)=O)c3C)CC2)c1C</smiles><smiles>CC(=O)c1cc(-c2ccccc2)n(CCC[Si](C)(C)O[Si](C)(C)CCCn2c(-c3ccccc3)cc(C(C)=O)c2C)c1C</smiles>

1k (55\%)<smiles>CC(=O)c1cc(-c2cccs2)n(CCC[Si](C)(C)O[Si](C)(C)CCCn2c(-c3cccs3)cc(C(C)=O)c2C)c1C</smiles><smiles>COC(=O)c1cc(-c2ccco2)n(CCC[Si](C)(C)O[Si](C)(C)CCCn2c(-c3ccco3)cc(C(=O)OC)c2C)c1C</smiles>

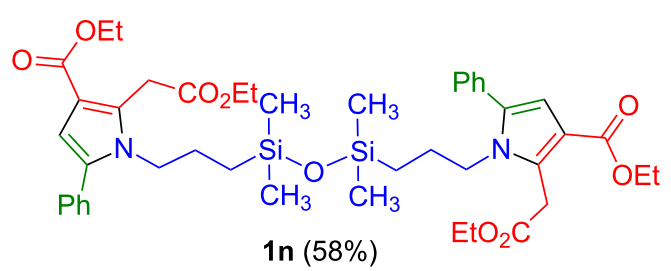<smiles>COC(=O)c1c2c(n(CCC[Si](C)(C)O[Si](C)(C)C)c1C)-c1ccccc1C2</smiles>

Figure 1: Scope of the synthesis of symmetrical bispyrrole derivatives. 
<smiles>CC(=O)CC(C)=O</smiles>

2c

$$
2 \stackrel{\mathrm{Ph}}{\stackrel{\mathrm{C}}{\mathrm{C}}} \mathrm{O}_{3}
$$

$4 a$

$\mathrm{NIS}, \mathrm{TsOH}(10 \mathrm{~mol} \%)$, $\operatorname{HSVM}\left(20 \mathrm{~s}^{-1}\right), 60 \mathrm{~min}$<smiles>CC(=O)/C=C(/C)NCCN(CCN/C(C)=C\C(C)=O)CCN/C(C)=C\C(C)=O</smiles>

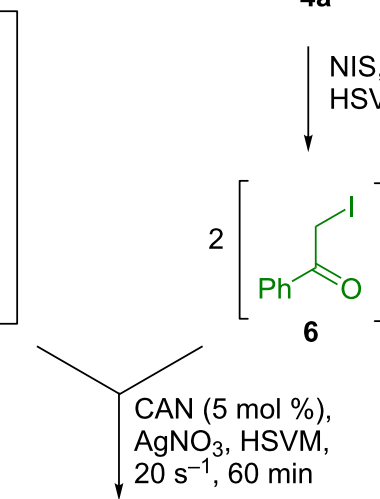<smiles>CC(=O)c1cc(-c2ccccc2)n(CCCN(CCn2c(-c3ccccc3)cc(C(C)=O)c2C)CCn2c(-c3ccccc3)cc(C(C)=O)c2C)c1C</smiles>

$8(35 \%)$

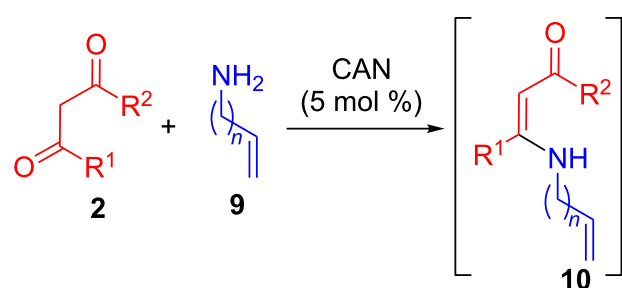<smiles></smiles>

$4 \mathrm{NIS}, \mathrm{TsOH}(10 \mathrm{~mol} \%)$ $\operatorname{HSVM}\left(20 \mathrm{~s}^{-1}\right), 60 \mathrm{~min}$

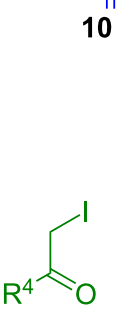

6

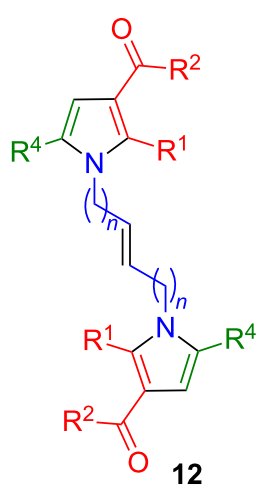


be $E$, while compound $\mathbf{1 2 c}$, obtained from a 1-homoallyl derivative, was isolated as a 1:1 E/Z mixture (Table 1).

Table 1: Yields of the cross-metathesis reactions

\begin{tabular}{lllllll} 
Cmpd & $\mathrm{R}^{1}$ & $\mathrm{R}^{2}$ & $\mathrm{R}^{4}$ & $n$ & $\mathbf{1 1}, \%$ & $\mathbf{1 2}, \%$ \\
\hline a & $\mathrm{CH}_{3}$ & OMe & 2-furyl & 1 & 87 & 88 \\
b & $\mathrm{CH}_{3}$ & $\mathrm{Me}$ & $\mathrm{C}\left(\mathrm{CH}_{3}\right)_{3}$ & 1 & 60 & $70^{\mathrm{a}}$ \\
c & $\mathrm{CH}_{3}$ & OMe & 2-thienyl & 2 & 71 & $80^{\mathrm{b}}$ \\
d & $\mathrm{CH}_{2}-\mathrm{CO}_{2} \mathrm{Et}$ & OEt & 2-furyl & 1 & 80 & 88 \\
\hline
\end{tabular}

aThe reaction time was $48 \mathrm{~h}$ in this case. ${ }^{\mathrm{b}} \mathrm{As}$ a $1: 1 \mathrm{E} / \mathrm{Z}$ mixture.

\section{Conclusion}

Symmetrical compounds containing two or three pyrrole or fused pyrrole units joined by a spacer are of interest in the exploration of heterocyclic chemical space. Such compounds were readily accessible in a single operation via the construction of their pyrrole fragments by means of mechanochemical multicomponent reactions that were performed starting from very simple starting materials and catalysts. Related compounds having a double bond in their spacer chain were obtained by a different approach involving the homodimerization of 1-allyl- or 1-homoallylpyrroles by cross-metathesis.

\section{Supporting Information}

\section{Supporting Information File 1}

Experimental details and NMR spectra.

[http://www.beilstein-journals.org/bjoc/content/ supplementary/1860-5397-13-190-S1.pdf]

\section{Acknowledgements}

Financial support from Ministerio de Economía y Competitividad, MINECO (grant CTQ2015-68380-R) is gratefully acknowledged. We also thank Laura Golchert for experimental assistance.

\section{References}

1. Lv, Z.; Chu, Y.; Wang, Y. HIVIAIDS 2015, 7, 95-104. doi:10.2147/HIV.S79956

2. Staderini, M.; Legname, G.; Bolognesi, M. L.; Menéndez, J. C. Curr. Top. Med. Chem. 2013, 13, 2491-2503. doi:10.2174/15680266113136660176

3. De Petrocellis, L.; Arroyo, F. J.; Orlando, P.; Schiano Moriello, A.; Vitale, R. M.; Amodeo, P.; Sánchez, A.; Roncero, C.; Bianchini, G.; Martín, M. A.; López-Alvarado, P.; Menéndez, J. C. J. Med. Chem. 2016, 59, 5661-5683. doi:10.1021/acs.jmedchem.5b01448

4. Stolle, A.; Szuppa, T.; Leonhardt, S. E. S.; Ondruschka, B. Chem. Soc. Rev. 2011, 40, 2317-2329. doi:10.1039/c0cs00195c
5. James, S. L.; Adams, C. J.; Bolm, C.; Braga, D.; Collier, P.; Friščić, T.; Grepioni, F.; Harris, K. D. M.; Hyett, G.; Jones, W.; Krebs, A.; Mack, J.; Maini, L.; Orpen, A. G.; Parkin, I. P.; Shearouse, W. C.; Steed, J. W.; Waddell, D. C. Chem. Soc. Rev. 2012, 41, 413-447. doi:10.1039/C1CS15171A

6. Bowmaker, G. A. Chem. Commun. 2013, 49, 334-348. doi:10.1039/C2CC35694E

7. Wang, G.-W. Chem. Soc. Rev. 2013, 42, 7688-7700. doi:10.1039/C3CS35526H

8. Claramunt, R. M.; López, C.; Sanz, D.; Elguero, J. Adv. Heterocycl. Chem. 2014, 112, 117-143. doi:10.1016/B978-0-12-800171-4.00003-2

9. Hernández, J. G.; Avila-Ortiz, C. G.; Juaristi, E. Useful Chemical Activation Alternatives in Solvent-Free Organic Reactions. In Comprehensive Organic Synthesis, 2nd ed.; Molander, G. A.; Knochel, P., Eds.; Elsevier: Oxford, 2014; Vol. 9, pp 287-314. doi:10.1016/B978-0-08-097742-3.00935-6

10. Hernández, J. G.; Friščić, T. Tetrahedron Lett. 2015, 56, 4253-4265. doi:10.1016/j.tetlet.2015.03.135

11. Do, J.-L.; Friščić, T. ACS Cent. Sci. 2017, 3, 13-19. doi:10.1021/acscentsci.6b00277

12. Hernández, J. G.; Bolm, C. J. Org. Chem. 2017, 82, 4007-4019. doi:10.1021/acs.joc.6b02887

13. Davor, M.; Štrukil, V., Eds. Mechanochemical Organic Synthesis; Elsevier, 2016.

14. Estévez, V.; Villacampa, M.; Menéndez, J. C. Chem. Commun. 2013, 49, 591-593. doi:10.1039/C2CC38099D

15. Estévez, V.; Sridharan, V.; Sabaté, S.; Villacampa, M.; Menéndez, J. C. Asian J. Org. Chem. 2016, 5, 652-662. doi:10.1002/ajoc.201600061

16. Zhao, H.; Dietrich, J. Expert Opin. Drug Discovery 2015, 10, 781-790. doi:10.1517/17460441.2015.1041496

17. Sridharan, V.; Menéndez, J. C. Chem. Rev. 2010, 110, 3805-3849. doi:10.1021/cr100004p

18. Mills, J. S.; Showell, G. A. Expert Opin. Invest. Drugs 2004, 13, 1149-1157. doi:10.1517/13543784.13.9.1149

19. Gately, S.; West, R. Drug Dev. Res. 2007, 68, 156-163. doi:10.1002/ddr.20177

20. Franz, A. K.; Wilson, S. O. J. Med. Chem. 2013, 56, 388-405. doi:10.1021/jm3010114

\section{License and Terms}

This is an Open Access article under the terms of the Creative Commons Attribution License (http://creativecommons.org/licenses/by/4.0), which permits unrestricted use, distribution, and reproduction in any medium, provided the original work is properly cited.

The license is subject to the Beilstein Journal of Organic Chemistry terms and conditions: (http://www.beilstein-journals.org/bjoc)

The definitive version of this article is the electronic one which can be found at: doi:10.3762/bjoc. 13.190 